\title{
Real-World Treatment of Enterococcal Infections with Daptomycin: Insights from a Large European Registry (EU-CORE)
}

\author{
Christoph Lübbert · Arne C. Rodloff · Kamal Hamed (1)
}

To view enhanced content go to www.infectiousdiseases-open.com

Received: May 23, 2015 / Published online: July 14, 2015

(C) The Author(s) 2015. This article is published with open access at Springerlink.com

\section{ABSTRACT}

Introduction: Evolution of antibacterial resistance in pathogenic enterococcal strains poses a growing therapeutic challenge. Daptomycin, a cyclic lipopeptide, exhibits broad antibiotic activity against Gram-positive bacteria.

Methods: The European Cubicin ${ }^{\circledR}$ Outcomes Registry and Experience, a multicenter, retrospective, non-interventional study, recorded clinical outcomes following daptomycin treatment.

Electronic supplementary material The online version of this article (doi:10.1007/s40121-015-0072-z) contains supplementary material, which is available to authorized users.

C. Lübbert

Division of Infectious Diseases and Tropical

Medicine, Department of Gastroenterology and

Rheumatology, Leipzig University Hospital, Leipzig,

Germany

A. C. Rodloff

Institute for Medical Microbiology and

Epidemiology of Infectious Diseases, Leipzig

University Hospital, Leipzig, Germany

K. Hamed ( $\square)$

Novartis Pharmaceuticals Corporation,

East Hanover, NJ, USA

e-mail: kamal.hamed@novartis.com
Results: Overall, 472 patients (predominantly elderly Caucasian males) were treated for enterococcal infections. Of those, $72.7 \%$ received antibiotics prior to daptomycin treatment, whereas $77.1 \%$ received other antibiotics concomitantly. Failure of previous therapy, resistant or non-susceptible pathogen, and narrowing of antibiotic therapy were the main reasons for switching to daptomycin treatment. Nosocomial infections comprised $55.8 \%$ of the cohort. Bacteremia (29.9\%), complicated skin and soft tissue infection (29.2\%) and endocarditis (12.3\%) were the most common primary infections. Clinical success was achieved in $77.1 \%$ of patients, with similar success rates across all primary infection categories. The overall clinical success rate was marginally higher $(82.5 \%$ vs $74.6 \%, p=0.09)$ with daptomycin use as first-line versus secondline therapy. Patients receiving higher doses of daptomycin exhibited the highest clinical success rates $(85.7 \%$ for $\geq 8 \mathrm{mg} / \mathrm{kg} /$ day vs $75.8 \%$ for $<8 \mathrm{mg} / \mathrm{kg} /$ day, $p=0.08)$. While $81(17.2 \%)$ patients reported at least one adverse event (AE), only $11(2.3 \%)$ and 3 (0.6\%) had treatment-related AEs and serious AEs, respectively. Separate microbiologic findings 
from Leipzig University Hospital demonstrate small proportions of Enterococcus faecium isolates with daptomycin minimum inhibitory concentrations $=4 \mathrm{mg} / \mathrm{L} \quad(4 \%) \quad$ or $\geq 8 \mathrm{mg} / \mathrm{L}$ $(0.8 \%)$, which are regarded as non-susceptible.

Conclusion: For enterococcal infections, daptomycin appears to be an effective and well-tolerated treatment option, exhibiting highest clinical success rates at higher doses.

Keywords: Daptomycin;

Enterococcal infections; EU-CORE; Gram-positive infections; VRE

\section{INTRODUCTION}

Enterococci are facultative anaerobic bacteria tolerant of a wide range of environmental conditions and constitute normal commensal flora of the human gastrointestinal tract. Some species of this genus have a high intrinsic resistance to antibiotics $[1,2]$. In addition, over the last two decades, particularly virulent strains of enterococci with acquired resistance to antibiotics, such as vancomycin, have emerged. Thus, associated treatment and infection control have become increasingly difficult [3]. The constitutive presence of enterococci in gastrointestinal tracts of hospitalized patients has assisted the transition from commensal organisms to nosocomial pathogens and the evolution of such drug resistance $[4,5]$. Moreover, establishment of such multidrugresistant pathogens is particularly common and therapeutically problematic in the hospital setting [6, 7], and thus constitutes a significant and growing public health challenge $[8,9]$.

Enterococci are often encountered in mixed infections and are particularly found in urinary tract infections, bacteremia, endocarditis, diverticulitis, peritonitis, and meningitis [3]. In recent years, the prevalence of species other than Enterococcus faecalis has increased. Particular Enterococcus faecium strains frequently showing multidrug resistance and non-susceptibility to vancomycin have emerged. Few therapeutic options are available for treating infections caused by vancomycinresistant enterococci (VRE) [6].

Daptomycin is a cyclic lipopeptide with rapid bactericidal activity against a wide range of Gram-positive bacteria, including multidrugresistant enterococci [10-14], and is effective in inhibiting or disrupting biofilm production in vitro [15-17]. Its mechanism of action is distinct from that of other antibiotics, including $\beta$-lactams, aminoglycosides, glycopeptides, fluoroquinolones, and macrolides. In the presence of physiological concentrations of ionized calcium, daptomycin interacts with the surface of Gram-positive bacteria, leading to disruption of membrane function [18].

Daptomycin was first approved in 2003, and is indicated for the treatment of complicated skin and soft tissue infections (cSSTIs; $4 \mathrm{mg} / \mathrm{kg}$ every $24 \mathrm{~h}$ ), right-sided endocarditis due to Staphylococcus aureus and for bacteremia associated with cSSTI or right-sided endocarditis (6 mg/kg every $24 \mathrm{~h}$ ) [19]. It has been previously shown that daptomycin $(6 \mathrm{mg} / \mathrm{kg} /$ day $)$ was highly effective against susceptible and multidrug-resistant $E$. faecalis and $E$. faecium in vitro and also in a rat model of experimental endocarditis [20]. Moreover, treatment with daptomycin in patients with invasive or bacteremic enterococcal infections leads to higher frequency of cure (up to $90 \%$ or more) when concomitant and adequate focus relief was performed [21].

The objective of this sub-analysis from the European Cubicin ${ }^{\circledR}$ Outcomes Registry and Experience (EU-CORE ${ }^{\mathrm{SM}}$ ) study was to evaluate the safety and clinical outcome of patients with 
enterococcal infections treated with daptomycin.

\section{METHODS}

\section{Patients and Data Collection}

Daptomycin use in a clinical setting frequently differs from controlled clinical trial or indicated use. EU-CORE is a retrospective, multicenter, multinational study conducted across 18 countries-12 in Europe (Austria, Bulgaria, France, Germany, Greece, Italy, Romania, Russia, Slovenia, Spain, Turkey, and United Kingdom), 5 in Latin America (Argentina, Brazil, Colombia, Mexico, and Venezuela) and 1 in Asia (India). It collected data on patients receiving daptomycin in a real-world clinical setting. Patients were enrolled into the study if they had been treated with at least one dose of daptomycin and for whom all mandatory information, as required in the case report forms, was recorded. Patients received daptomycin therapy between January 2006 and April 2012 and were followed up for 30 days after the end of treatment. Two-year follow-up data were collected until 2014 for patients with endocarditis, intracardiac/ intravascular device infection, osteomyelitis, or orthopedic device infection. A written informed consent was obtained when required by the Institutional Review Board/Ethical Committee and/or local data privacy regulations. Patients who received daptomycin as part of a controlled clinical trial were not eligible for inclusion in the study. Interim results of the EU-CORE registry were previously reported $[22,23]$.

A standardized case report form and protocol were used to collect demographic and clinical information on patients who had been treated with daptomycin. Demographic, antibiotic, microbiologic, and clinical data were collected from medical records at each site. Data collection was carried out as previously described by Gonzalez-Ruiz et al. [19].

\section{Clinical Outcomes and Safety}

Investigators assessed the clinical outcome at the end of daptomycin therapy according to the following protocol-defined criteria: cured, clinical signs and symptoms resolved, no additional antibiotic therapy was necessary, or infection cleared with a negative culture reported; improved, partial resolution of clinical signs and symptoms and/or additional antibiotic therapy was warranted; failed, inadequate response to daptomycin therapy, worsening or new/recurrent signs and symptoms, need for a change in antibiotic therapy, or a positive culture reported at the end of therapy; and non-evaluable, unable to determine response due to insufficient information [24].

Clinical success was used to collectively describe patients with an outcome of cured or improved. Time to improvement was also recorded. Duration of treatment was measured as the number of inpatient and outpatient days during which the patient received daptomycin therapy, even if these were non-consecutive. There were no restrictions on concomitant treatment in the EU-CORE study. The safety population comprised all eligible patients who had any safety parameters assessed, and the efficacy population comprised all eligible patients for whom clinical outcome was assessed. Safety was assessed for up to 30 days after the end of daptomycin treatment.

All reported deaths, adverse events (AEs) and serious AEs (SAEs), regardless of their relationship to daptomycin, were recorded, and the severity of AEs was determined. 


\section{Microbiology}

For the EU-CORE study, antibiotic susceptibility profiles based on testing performed at the local laboratories were listed for each bacterial species. Antibiograms were analyzed through tabulations of susceptibility classifications (defined as susceptible/intermediate/resistant) based on the susceptibility breakpoints used by the local laboratory and minimum inhibitory concentration (MIC) values when available.

For all enterococcal isolates from the Leipzig University Hospital, Germany, MICs were determined using the ISO 20776-1 (http:// www.iso.org) microbroth dilution method. Susceptibilities were assessed using breakpoints established by the Clinical Laboratory Standards Institute (CLSI; http://www.clsi.org). The current CLSI susceptibility breakpoint for daptomycin is $\leq 4 \mathrm{mg} / \mathrm{L}$. In view of the limited clinical data available, the European Committee on Antimicrobial Susceptibility Testing (EUCAST; http://www.eucast.org) has published the epidemiological cutoff values of $4 \mathrm{mg} / \mathrm{L}$ for both E. faecalis and E. faecium.

\section{Statistical Analysis}

Statistical analysis was performed using SAS version 9.3 (SAS Institute Inc., Cary, NC, USA). Numerical variables were summarized as arithmetic mean, standard deviation, median, minimum, first quartile, third quartile, and maximum for continuous variables. Categorical variables were summarized by absolute and relative frequencies, and missing values were not included in the calculation of relative frequencies. Categorical data were analyzed by the Chi-square or Fisher's exact test and $p$ values (two-tailed) of $<0.05$ were considered to be statistically significant.

\section{RESULTS}

\section{Patient Demographic and Clinical Characteristics}

Of the 6075 patients (5467 from Europe, 409 from Latin America and 199 from Asia) enrolled in the EU-CORE study, 472 (7.8\%) patients had enterococcal infections as the primary diagnosis. All were included in both the safety and efficacy populations (Table 1).

Patients were predominantly adults with a median age of 65 (range 1-94) years and a median body weight of 75 (range 6-177) $\mathrm{kg}$. The majority were male $(63.3 \%)$ and Caucasian (87.7\%; Table 1). Comorbidity was frequent, as would be expected in patients with invasive enterococcal infections. Cardiovascular disease was the most common underlying disease, reported in $55.9 \%$ of the cohort, followed by diabetes mellitus (27.8\%), renal disease $(22.0 \%)$, gastrointestinal disease (21.0\%), cancer (19.5\%), and pulmonary disease (13.6\%).

Of the 163 patients for whom data were available, 91 (55.8\%) patients acquired nosocomial infections, 63 (38.7\%) patients acquired infection in a community setting, and 9 (5.5\%) patients in a nursing home/ extended care setting.

\section{Primary Infections}

Of the wide range of primary infection types treated with daptomycin, bacteremia (29.9\%), cSSTI (29.2\%) and endocarditis (12.3\%) were the most common (Table 2). Patients with foreign body/prosthetic infection (8.5\%), urinary tract infection/pyelonephritis (4.7\%), osteomyelitis (4.4\%), and infections classified as other $(11 \%)$ were also enrolled. 
Table 1 Demographic and clinical characteristics

\begin{tabular}{|c|c|c|}
\hline \multirow{2}{*}{$\begin{array}{l}\text { Characteristics } \\
\text { Age (years), median (range) }\end{array}$} & \multicolumn{2}{|c|}{$N=472$} \\
\hline & 65 & $(1-94)$ \\
\hline \multicolumn{3}{|l|}{ Age (years), $n(\%)$} \\
\hline$<65$ (including $<18$ ) & 236 & $(50.0)$ \\
\hline$<18$ & 5 & $(1.1)$ \\
\hline$\geq 65$ (including $\geq 75$ ) & 236 & $(50.0)$ \\
\hline$\geq 75$ & 110 & $(23.3)$ \\
\hline \multicolumn{3}{|l|}{ Gender, $n(\%)$} \\
\hline Male & 299 & $(63.3)$ \\
\hline \multicolumn{3}{|l|}{ Ethnicity, $n(\%)$} \\
\hline Caucasian & 414 & $(87.7)$ \\
\hline Body weight $(\mathrm{kg})$, median (range) & 75 & $(6-177)$ \\
\hline \multicolumn{3}{|c|}{ Frequent significant underlying disease, $n(\%)$} \\
\hline Cardiovascular disease & 264 & $(55.9)$ \\
\hline Diabetes mellitus & 131 & $(27.8)$ \\
\hline Renal disease & 104 & $(22.0)$ \\
\hline Gastrointestinal disease & 99 & $(21.0)$ \\
\hline Malignancy & 92 & $(19.5)$ \\
\hline Pulmonary disease & 64 & $(13.6)$ \\
\hline \multicolumn{3}{|l|}{ Renal function, $n(\%)$} \\
\hline Creatinine clearance $<30 \mathrm{~mL} / \mathrm{min}$ & 68 & $(14.8)$ \\
\hline \multicolumn{3}{|c|}{ Setting prior to onset of infection, $n(\%)^{\mathrm{a}}$} \\
\hline Hospital & 91 & $(55.8)$ \\
\hline Nursing home/extended care & 9 & $(5.5)$ \\
\hline Community & 63 & $(38.7)$ \\
\hline Unknown & 309 & \\
\hline
\end{tabular}

a Denominators of different settings excluded patients with unknown information

\section{Previous and Concomitant Antibiotic Therapies}

Of the 472 patients, $343(72.7 \%)$ patients received antibiotics prior to daptomycin therapy. While 152 (32.2\%) patients received penicillins, 132 (28.0\%) received glycopeptides (of whom 93 [19.7\%] were administered vancomycin as a prior therapy). Furthermore, 108 (22.9\%) patients received carbapenems and 91 (19.3\%) patients received cephalosporins.

The main reasons for switching to daptomycin were failure of previous antibiotic therapy $(32.6 \%)$, a resistant or non-susceptible pathogen (14.4\%), toxicity/intolerance $(8.7 \%)$, and narrowing of antibiotic therapy (8.1\%). Concomitant antibiotic therapy with daptomycin was received by 357 (77.1\%) inpatients; carbapenems (35.4\%), $\beta$-lactams (26.9\%), and fluoroquinolones (11.7\%) were the most frequently used concomitant antibiotics.

\section{Daptomycin Prescribing Patterns}

The most commonly prescribed dose of daptomycin was $6 \mathrm{mg} / \mathrm{kg} /$ day $(47.0 \%)$, and $20.1 \%$ of patients received $>6 \mathrm{mg} / \mathrm{kg} /$ day (Table 3). A dose of $>6 \mathrm{mg} / \mathrm{kg} /$ day was most frequently administered in endocarditis, osteomyelitis and foreign body/prosthetic infection. The median duration of daptomycin therapy was 12 (range 1-83) days for inpatients $(n=461)$ and 19 (range 3-68) days for outpatients $(n=36)$.

\section{Clinical Outcomes}

Overall clinical success rate was 77.1\%. Notably, only $7.2 \%$ of patients were documented as having failed treatment and $15.7 \%$ of patients were non-evaluable. Rates of clinical success across different infections and infecting enterococcal pathogens are shown in Figs. 1 and 2 , respectively. The overall clinical success rate for different infections was slightly higher 
Table 2 Type of primary infection and enterococcal pathogen

\begin{tabular}{|c|c|c|c|c|}
\hline \multirow[t]{2}{*}{ Primary infection } & \multirow{2}{*}{$\begin{array}{l}\text { Patients, } \\
n(\%)\end{array}$} & \multicolumn{3}{|c|}{ Enterococcal pathogen } \\
\hline & & $\begin{array}{l}\text { Enterococcus } \\
\text { faecalis, } \\
n(\%)\end{array}$ & $\begin{array}{l}\text { Enterococcus } \\
\text { faecium, } \\
n(\%)\end{array}$ & $\begin{array}{l}\text { Enterococcus } \\
\text { species, } \\
n(\%)\end{array}$ \\
\hline Bacteremia & $141(29.9)$ & $58(41.1)$ & $72(51.1)$ & $11(7.8)$ \\
\hline $\begin{array}{l}\text { Complicated skin and soft tissue } \\
\text { infection }\end{array}$ & $138(29.2)$ & $71(51.4)$ & $54(39.1)$ & $13(9.4)$ \\
\hline Endocarditis & $58(12.3)$ & $43(74.1)$ & $8(13.8)$ & $7(12.1)$ \\
\hline Foreign body/prosthetic infection & $40(8.5)$ & $27(67.5)$ & $9(22.5)$ & $4(10.0)$ \\
\hline Urinary tract infection/pyelonephritis & $22(4.7)$ & $7(31.8)$ & $10(45.5)$ & $5(22.7)$ \\
\hline Osteomyelitis & $21(4.4)$ & $14(66.7)$ & $6(28.6)$ & $1(4.8)$ \\
\hline Other $^{\mathrm{a}}$ & $52(11.0)$ & $16(30.8)$ & $25(48.1)$ & $11(21.2)$ \\
\hline Total & $472(100.0)$ & $236^{\mathrm{b}}(50.0)$ & $184^{\mathrm{c}}(39.0)$ & $52(11.0)$ \\
\hline
\end{tabular}

${ }^{a}$ Includes uncomplicated skin and soft tissue infection, necrotizing infections, central nervous system infection, surgical/ non-surgical antibiotic prophylaxis, metastatic abscess, septic arthritis, or not otherwise specified

${ }^{\mathrm{b}}$ Vancomycin-resistant E. faecalis $=18 / 236$ (3.8\%): three bacteremia, six complicated skin and soft tissue infection, three foreign body/prosthetic infection, two urinary tract infection/pyelonephritis, three osteomyelitis, and one other

${ }^{c}$ Vancomycin-resistant E. faecium $=46 / 184$ (9.7\%): 25 bacteremia, nine complicated skin and soft tissue infection, three endocarditis, three foreign body/prosthetic infection, two urinary tract infection/pyelonephritis, and four other

Table 3 Daptomycin dose by primary infection

\begin{tabular}{|c|c|c|c|c|c|c|}
\hline \multirow[t]{2}{*}{ Primary infection } & \multirow{2}{*}{$\begin{array}{l}\text { Patients, } \\
n(\%)\end{array}$} & \multicolumn{5}{|c|}{ Daptomycin dose } \\
\hline & & $\begin{array}{l}4 \mathrm{mg} / \\
\mathrm{kg} / \mathrm{day}, \\
n(\%)\end{array}$ & $\begin{array}{l}6 \mathrm{mg} / \\
\mathrm{kg} / \mathrm{day} \\
n(\%)\end{array}$ & $\begin{array}{l}>6 \mathrm{mg} / \\
\mathrm{kg} / \mathrm{day}, \\
n(\%)^{\mathrm{a}}\end{array}$ & $\begin{array}{l}\geq 8 \mathrm{mg} / \\
\mathrm{kg} / \mathrm{day}, \\
n(\%)\end{array}$ & $\begin{array}{l}\text { Other dose, } \\
n(\%)^{b}\end{array}$ \\
\hline Bacteremia & $141(29.9)$ & $20(14.2)$ & $77(54.6)$ & $22(15.6)$ & $12(8.5)$ & $22(15.6)$ \\
\hline $\begin{array}{l}\text { Complicated skin and soft tissue } \\
\text { infection }\end{array}$ & $138(29.2)$ & $54(39.1)$ & $50(36.2)$ & $20(14.5)$ & $13(9.4)$ & $14(10.1)$ \\
\hline Endocarditis & $58(12.3)$ & $1(1.7)$ & $32(55.2)$ & $23(39.7)$ & $15(25.9)$ & $2(3.4)$ \\
\hline Foreign body/prosthetic infection & $40(8.5)$ & $3(7.5)$ & $19(47.5)$ & $15(37.5)$ & $12(30.0)$ & $3(7.5)$ \\
\hline Urinary tract infection/pyelonephritis & $22(4.7)$ & $13(59.1)$ & $8(36.4)$ & $1(4.5)$ & $0(0)$ & $0(0)$ \\
\hline Osteomyelitis & $21(4.4)$ & $3(14.3)$ & $9(42.9)$ & $8(38.1)$ & $6(28.6)$ & $1(4.8)$ \\
\hline Other $^{\mathrm{c}}$ & $52(11.0)$ & $9(17.3)$ & $27(51.9)$ & $6(11.5)$ & $5(9.6)$ & $10(19.2)$ \\
\hline Total & $472(100.0)$ & $103(21.8)$ & $222(47.0)$ & $95(20.1)$ & $63(13.3)$ & $52(11.0)$ \\
\hline
\end{tabular}




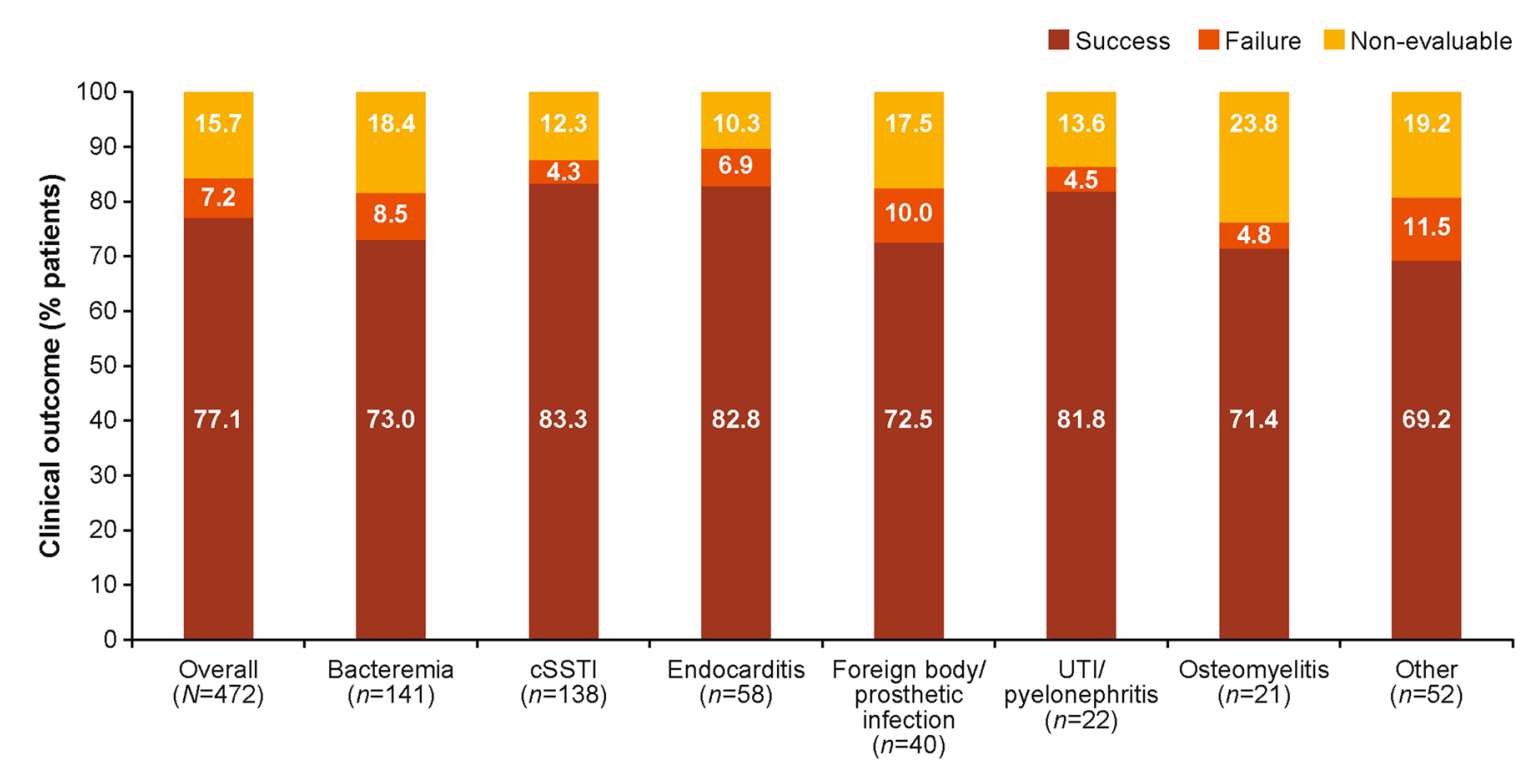

Fig. 1 Clinical outcome by primary infection type. cSSTI complicated skin and soft tissue infection, UTI urinary tract infection

when daptomycin was used as first-line (82.5\%) than second-line $(74.6 \%)$ therapy $(p=0.09)$.

The clinical success rate by infection type independent of the treatment dose ranged between $69.2 \%$ and $83.3 \%$. The clinical success rate for cSSTI was $83.3 \%$, endocarditis $82.8 \%$, urinary tract infection/pyelonephritis $81.8 \%$, bacteremia $73.0 \%$, foreign body/prosthetic infection 72.5\%, and osteomyelitis $71.4 \%$ (Fig. 1). Clinical success rates were overall similar for doses $<8 \mathrm{mg} / \mathrm{kg} /$ day $(75.8 \%)$, but were higher in patients treated with doses $\geq 8 \mathrm{mg} / \mathrm{kg}$ /day $(85.7 \%, p=0.08)$. The median time to improvement was 4 (range 1-30) days from initiation of daptomycin treatment. Overall, clinical success rates were similar whether patients received no concomitant antibiotic therapy $(78.0 \%)$ or any concomitant antibiotic therapy (77.3\%).

\section{Microbiology}

On the basis of the reported percentage of susceptible isolates, daptomycin was more active than vancomycin against $E$. faecalis (94.9\% vs $89.1 \%$ ), E. faecium (96.9\% vs $66.2 \%$ ), and Enterococcus species $(83.3 \%$ vs $56.4 \%$; Table 4).

Susceptibility data of enterococci to daptomycin stating the exact MICs were not available from the EU-CORE registry. To address this issue, the MIC determinations for daptomycin for primary isolates of $E$. faecalis and $E$. faecium strains detected in clinical specimens at the Leipzig University Hospital, Germany, in 2014 were analyzed (Fig. 3). Displaying the expected Gaussian distribution curve, the data showed only small proportions of $E$. faecalis and $E$. faecium isolates with daptomycin $\mathrm{MICs}=4 \mathrm{mg} / \mathrm{L} \quad(1.9 \%$ and $4 \%$, respectively) or $\geq 8 \mathrm{mg} / \mathrm{L} \quad(1.3 \%$ and $0.8 \%$, respectively). Among these $E$. faecalis and E. faecium isolates, the VRE rate was $0.8 \%$ and $36.2 \%$, respectively. Using the current CLSI susceptibility breakpoint for daptomycin $(\leq 4 \mathrm{mg} / \mathrm{L})$, resistance rates of $1.3 \%$ for E. faecalis and $0.8 \%$ for E. faecium need to be considered. 
Success $\square$ Failure Non-evaluable

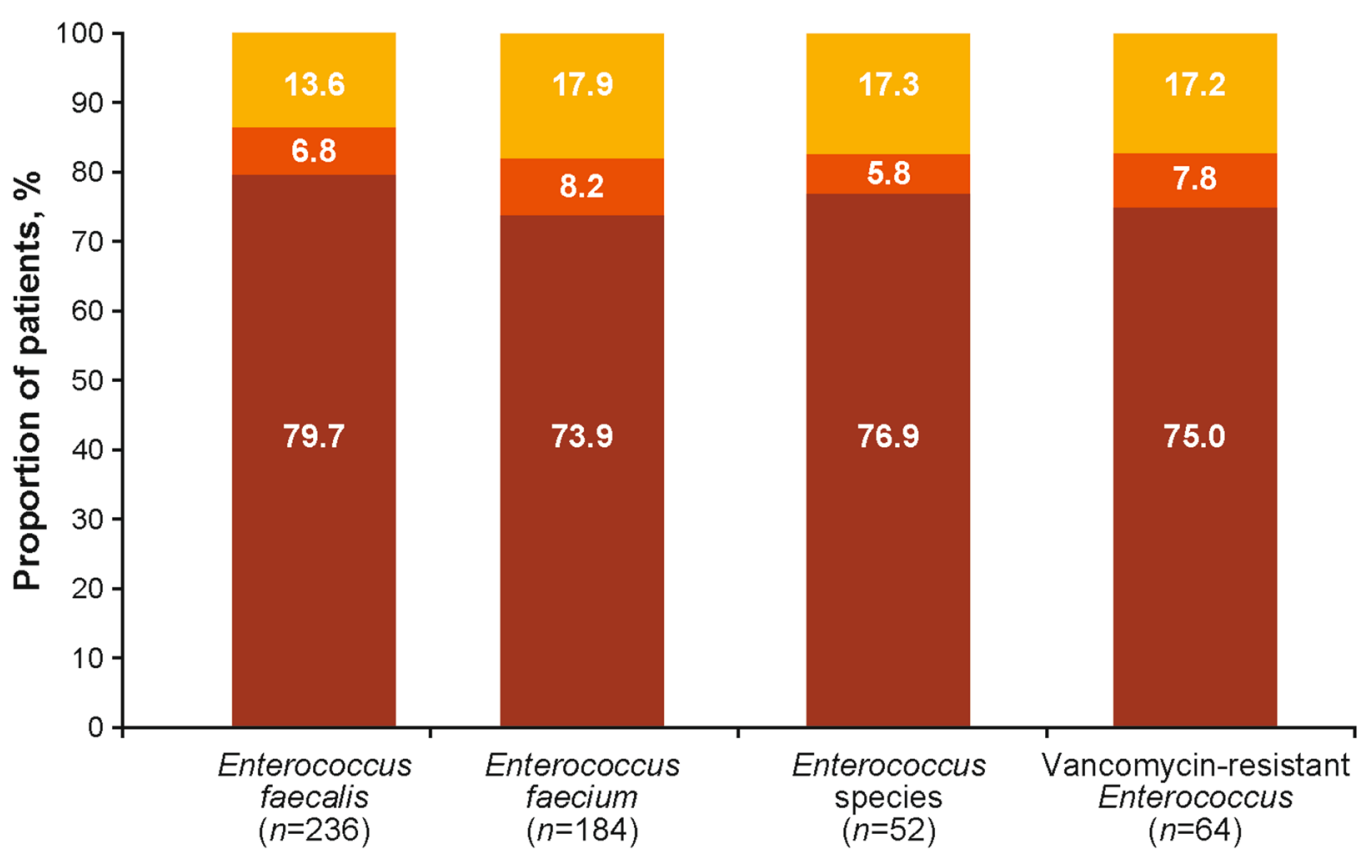

Fig. 2 Clinical outcome by primary infecting enterococcal pathogen

Table 4 Reported enterococcal susceptibility to daptomycin and vancomycin

\begin{tabular}{llcclc}
\hline Pathogen & Drug & $\begin{array}{l}\text { Patients, } \\
(\boldsymbol{n})\end{array}$ & $\begin{array}{l}\text { Susceptible, } \\
\boldsymbol{n}(\%)\end{array}$ & $\begin{array}{l}\text { Intermediate susceptible, } \\
\boldsymbol{n}(\%)\end{array}$ & $\begin{array}{l}\text { Resistant, } \\
\boldsymbol{n}(\%)\end{array}$ \\
\hline Enterococcus faecalis & Daptomycin & 99 & $94(94.9)$ & - & $3(3.0)$ \\
& Vancomycin & 201 & $179(89.1)$ & $2(1.0)$ & $18(9.0)$ \\
Enterococcus faecium & Daptomycin & 65 & $63(96.9)$ & $1(1.5)$ & - \\
& Vancomycin & 154 & $102(66.2)$ & - & $46(29.9)$ \\
Enterococcus species & Daptomycin & 18 & $15(83.3)$ & $1(5.6)$ & $1(5.6)$ \\
& Vancomycin & 39 & $22(56.4)$ & $3(7.7)$ & $14(35.9)$ \\
\hline
\end{tabular}

Susceptibility data of isolates from some patients were missing

\section{Safety}

A total of $81(17.2 \%)$ patients reported at least one $\mathrm{AE}$ and 63 (13.3\%) reported SAEs. The most common AEs ( $>1 \%$ patients) are listed in Table 5. Most AEs and SAEs were considered as unrelated to daptomycin treatment by the investigator, with $11(2.3 \%)$ and 3 (0.6\%) treatment-related AEs and SAEs, respectively, being recorded. A total of $46(9.7 \%)$ patients died during the study or follow-up (Table 5). The main causes of death were multi-organ failure, sepsis and septic shock. Discontinuation of daptomycin treatment due to an AE occurred in $6.1 \%$ of patients. There were a total of five patients with rhabdomyolysis AEs and SAEs, of whom three were considered by the investigator as possibly treatment related (two AEs and one $\mathrm{SAE}$ ). Of the patients with treatment-related rhabdomyolysis, two discontinued the study. 


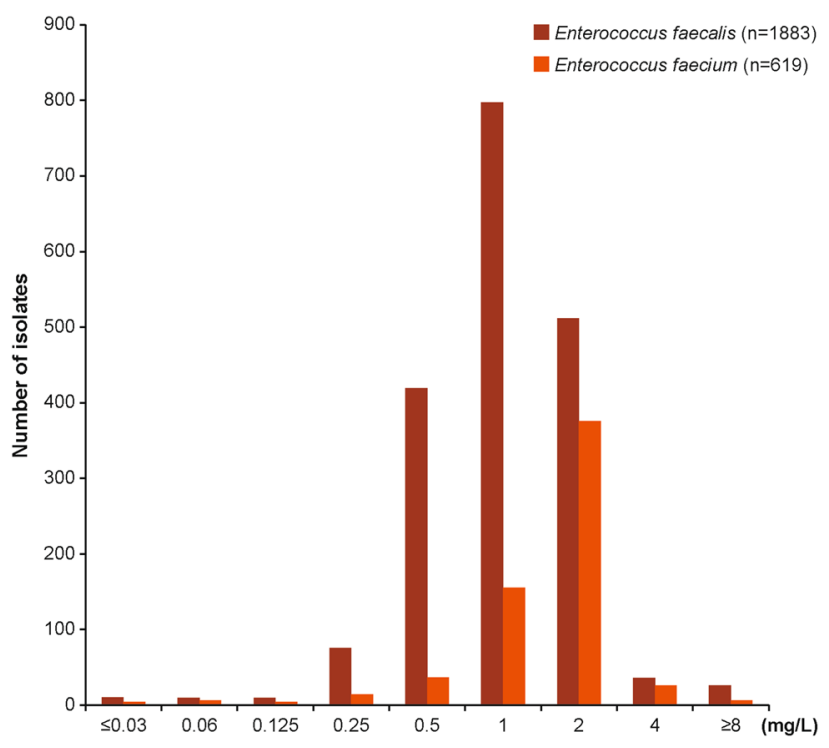

Fig. 3 Daptomycin susceptibility of enterococci-Leipzig University Hospital, Germany, January to December 2014

Table 5 Safety of daptomycin treatment

\begin{tabular}{lc}
\hline Safety parameters & $\begin{array}{l}N=472 \\
n(\%)\end{array}$ \\
\hline Deaths & $46(9.7)$ \\
Serious adverse events & $63(13.3)$ \\
Adverse events & $81(17.2)$ \\
Adverse events leading to permanent drug & $29(6.1)$ \\
discontinuation & \\
Adverse events occurring in $>1 \%$ of patients & \\
Multi-organ failure & $12(2.5)$ \\
Septic shock & $10(2.1)$ \\
Sepsis & $9(1.9)$ \\
Blood creatine phosphokinase increased & $5(1.1)$ \\
\hline
\end{tabular}

No AEs of eosinophilic pneumonia were reported.

Serum creatine phosphokinase (CPK) was measured at baseline for 293 patients, and the majority $(85.0 \%)$ had normal values. At baseline, four (1.4\%) patients had CPK levels $>10 \times$ upper limit of normal (ULN). Eight patients had a shift of CPK elevation from $\leq 10 \times$ ULN at baseline to $>10 \times$ ULN. Increased blood CPK was reported as an $\mathrm{AE}$ in five $(1.1 \%)$ patients and as an SAE in one (0.2\%) patient.

\section{DISCUSSION}

The EU-CORE study illustrates real-world usage of daptomycin in the treatment of enterococcal infections. The many multinational sites enrolled in the EU-CORE study allowed a wide spectrum of patients. Overall, treatment of enterococcal infections with daptomycin was associated with high rates of clinical success. Daptomycin showed good effectiveness whether used as first- or second-line therapy.

Available interventions for VRE are mostly based on expert opinion recommendations [25]. A recent meta-analysis has showed that the two most commonly prescribed drugs, daptomycin and linezolid, were equally efficacious in blood stream infections due to VRE [26]. A 2-year retrospective study conducted at the Detroit Medical Center also showed that daptomycin was as efficacious as linezolid and $\beta$-lactams in 
treating bacteremia due to VRE [27]. However, prolonged linezolid treatment has been associated with multiple safety concerns [28, 29].

Daptomycin has previously been shown to be active against Enterococcus species with vancomycin non-susceptible $E$. faecalis and E. faecium being $100.0 \%$ and $99.8 \%$ susceptible to daptomycin, respectively [30]. In the current study, daptomycin was reported as microbiologically more active than vancomycin against Enterococcus species.

Although licensed differently, many clinicians recommend daptomycin at a higher dose of $8-10 \mathrm{mg} / \mathrm{kg} /$ day for complicated bacteremia and native valve endocarditis [31]. Kullar et al. assessed the clinical and microbiologic outcomes of high-dose daptomycin therapy and reported that daptomycin doses of $\geq 8 \mathrm{mg} / \mathrm{kg} /$ day may be safe and effective in patients with complicated Gram-positive infections (including Enterococcus species) [32]. In the EU-CORE study, high-dose treatment resulted in a marginally higher overall clinical success rate (85.7\% for doses $\geq 8 \mathrm{mg} / \mathrm{kg} /$ day compared with $75.8 \%$ for doses $<8 \mathrm{mg} / \mathrm{kg} /$ day). As daptomycin MICs for Enterococcus species are typically higher than those for other Gram-positive organisms (0.5-4 vs $0.25-1 \mathrm{mg} / \mathrm{L})$, patients with these serious infections may require higher doses of daptomycin for optimal treatment.

Recent microbiologic findings from the Leipzig University Hospital, Germany, which are not included in the EU-CORE data, demonstrate only small proportions of E. faecalis and E. faecium isolates with daptomycin $\quad \mathrm{MICs}=4 \mathrm{mg} / \mathrm{L} \quad$ or $\quad \geq 8 \mathrm{mg} / \mathrm{L}$ (Fig. 3). Among these E. faecalis and E. faecium isolates, the VRE rate was $0.8 \%$ and $36.2 \%$, respectively. Using the current CLSI susceptibility breakpoint for daptomycin ( $\leq 4 \mathrm{mg} / \mathrm{L})$, resistance rates of $1.3 \%$ for $E$. faecalis and $0.8 \%$ for $E$. faecium need to be considered. Previously, it was reported that high-dose ( $>6 \mathrm{mg} / \mathrm{kg} /$ day; median dose, $8.2 \mathrm{mg} / \mathrm{kg} /$ day) daptomycin treatment of enterococcal infections with MICs $\leq 4 \mathrm{mg} / \mathrm{L}$ was associated with high clinical success (81-100\%), whereas treatment was unsuccessful with high daptomycin MIC ( $\geq 8 \mathrm{mg} / \mathrm{L}$ ) [33]. Thus, high clinical cure rates would generally be expected when adequate concomitant source control is performed and when suggested MIC limits are respected.

The rates of AEs reported in this retrospective observational study were low and should not be compared to $\mathrm{AE}$ reporting during a randomized clinical trial. Daptomycin had generally a favorable safety profile with no new or unexpected safety findings in this population. SAEs and deaths were reflective of the severity of underlying infections and health status of patients.

These results complement data from randomized clinical studies [34] and show that daptomycin is a valuable treatment option in the management of enterococcal infections, especially with rising rates of multidrugresistant enterococci exhibiting resistance to standard enterococcal antibiotics (i.e., ampicillin, vancomycin and aminoglycosides).

There are limitations to this retrospective analysis of the EU-CORE registry data. First, it does not allow comparison of treatments as in a randomized trial. In addition, while prior and concomitant use of other antibiotic agents as well as presence of mixed infections were documented, this was not controlled and might have complicated the interpretation of clinical outcome. No blinding or independent evaluations were incorporated and patient outcomes were solely determined by the 
treating physician. Furthermore, disease severity was not accounted for in the analysis, and patient selection bias could not be discounted. However, variability in dosing and patient population reflects the real-world clinical setting for daptomycin use (i.e., treatment of diverse infections and concomitant use of antibiotics). It also provides a valuable insight into the real-world clinical practice (often sicker patients than those enrolled in clinical trials) and expands on the outcomes derived from the existing clinical trials.

\section{CONCLUSIONS}

Currently, there is not much comprehensive work published regarding optimal antibiotic selection for the treatment of VRE infections. Studies described in the literature are limited by small sample sizes, lack of patient-level data and inconsistent outcomes definitions. However, the data obtained in the EU-CORE study described here are encouraging and indicate a benefit of high-dose therapy. Future investigation, including randomized clinical trials adjusted to measured MIC levels, is warranted to support guidance for therapeutic regimens for VRE infections.

\section{ACKNOWLEDGMENTS}

This study and article processing charges were sponsored by Novartis Pharma AG. All named authors meet the ICMJE criteria for authorship for this manuscript, take responsibility for the integrity of the work as a whole, and have given final approval to the version to be published. The authors thank the patients for their participation and contribution to this study, as well as the investigators and the entire study team. Editorial assistance was provided by Novartis Global Medical and Clinical Services medical writers Neeta Pillai and Stephen Sullivan. Funding for writing was provided by Novartis Pharma AG.

Conflict of interest. Christoph Lübbert received financial support for consulting, lecture fees and travel costs from Astellas, InfectoPharm, MSD, Novartis, and Pfizer. Arne C Rodloff received financial support for consulting, lecture fees and travel costs from AstraZeneca, BAG, Biorad, Gilead, InfectoPharm, MSD, Novartis, Pfizer, Roche, and ThermoFischer. Kamal Hamed is an employee of Novartis Pharmaceuticals Corporation.

Compliance with ethics guidelines. The study has been performed in accordance with the ethical standards as laid down in the 1964 Declaration of Helsinki and its later amendments or comparable ethical standards. The protocol was approved by the health authority and the Institutional Review Board (IRB) or Ethics Committee (EC) in each country and written informed consent was obtained according to the requirements of the IRB or EC and/or the local data privacy regulations.

Open Access. This article is distributed under the terms of the Creative Commons Attribution Noncommercial License which permits any noncommercial use, distribution, and reproduction in any medium, provided the original author(s) and the source are credited. 


\section{REFERENCES}

1. Woodford N, Livermore DM. Infections caused by Gram-positive bacteria: a review of the global challenge. J Infect. 2009;59(Suppl 1):S4-16.

2. Bionda N, Fleeman RM, Shaw LN, Cudic P. Effect of ester to amide or $\mathrm{N}$-methylamide substitution on bacterial membrane depolarization and antibacterial activity of novel cyclic lipopeptides. Chem Med Chem. 2013;8(8):1394-402.

3. Fisher K, Phillips C. The ecology, epidemiology and virulence of Enterococcus. Microbiology. 2009;155(Pt 6):1749-57.

4. Arias CA, Contreras GA, Murray BE. Management of multidrug-resistant enterococcal infections. Clin Microbiol Infect. 2010;16(6):555-62.

5. Patel R. 2003. Clinical impact of vancomycinresistant enterococci. J Antimicrob Chemother 51 Suppl 3:iii13-21.

6. Linden PK. Treatment options for vancomycinresistant enterococcal infections. Drugs. 2002;62(3):425-41.

7. Arias CA, Murray BE. The rise of the Enterococcus: beyond vancomycin resistance. Nat Rev Microbiol. 2012;10(4):266-78.

8. Bouza E, Finch R. Infections caused by Grampositive bacteria: situation and challenges of treatment. Clin Microbiol Infect. 2001;7(Suppl 4):iii.

9. Courvalin P. Vancomycin resistance in grampositive cocci. Clin Infect Dis. 2006;42(Suppl 1):S25-34.

10. Cotroneo N, Harris R, Perlmutter N, Beveridge T, Silverman JA. Daptomycin exerts bactericidal activity without lysis of Staphylococcus aureus. Antimicrob Agents Chemother. 2008;52(6): 2223-5.

11. McDaneld PM, Spooner LM, Mohr JF, Belliveau PP. Use of daptomycin to treat infections with methicillin-resistant Staphylococcus aureus isolates having vancomycin minimum inhibitory concentrations of 1.5 to $2 \mu \mathrm{g} / \mathrm{mL}$. Ann Pharmacother. 2013;47(12):1654-65.

12. Hall AD, Steed ME, Arias CA, Murray BE, Rybak MJ. Evaluation of standard- and high-dose daptomycin versus linezolid against vancomycin-resistant Enterococcus isolates in an in vitro pharmacokinetic/pharmacodynamic model with simulated endocardial vegetations. Antimicrob Agents Chemother. 2012;56(6):3174-80.
13. Marconescu P, Graviss EA, Musher DM. Rates of killing of methicillin-resistant Staphylococcus aureus by ceftaroline, daptomycin, and telavancin compared to that of vancomycin. Scand J Infect Dis. 2012;44(8):620-2.

14. LaPlante KL, Rybak MJ. Impact of high-inoculum Staphylococcus aureus on the activities of nafcillin, vancomycin, linezolid, and daptomycin, alone and in combination with gentamicin, in an in vitro pharmacodynamic model. Antimicrob Agents Chemother. 2004;48(12):4665-72.

15. Raad I, Hanna H, Jiang Y, Dvorak T, Reitzel R, Chaiban G, Sheretz R, Hachem R. Comparative activities of daptomycin, linezolid, and tigecycline against catheter-related methicillin-resistant Staphylococcus bacteremic isolates embedded in biofilm. Antimicrob Agents Chemother. 2007;51(5):1656-60.

16. Leite B, Gomes F, Teixeira P, Souza C, Pizzolitto E, Oliveira R. In vitro activity of daptomycin, linezolid and rifampicin on Staphylococcus epidermidis biofilms. Curr Microbiol. 2011;63(3):313-7.

17. LaPlante KL, Woodmansee S. Activities of daptomycin and vancomycin alone and in combination with rifampin and gentamicin against biofilm-forming methicillin-resistant Staphylococcus aureus isolates in an experimental model of endocarditis. Antimicrob Agents Chemother. 2009;53(9):3880-6.

18. Silverman JA, Perlmutter NG, Shapiro HM. Correlation of daptomycin bactericidal activity and membrane depolarization in Staphylococcus aureus. Antimicrob Agents Chemother. 2003;47(8):2538-44.

19. Gonzalez-Ruiz A, Beiras-Fernandez A, Lehmkuhl H, Seaton RA, Loeffler J, Chaves RL. Clinical experience with daptomycin in Europe: the first 2.5 years. J Antimicrob Chemother. 2011;66(4):912-9.

20. Vouillamoz J, Moreillon P, Giddey M, Entenza JM. Efficacy of daptomycin in the treatment of experimental endocarditis due to susceptible and multidrug-resistant enterococci. J Antimicrob Chemother. 2006;58(6):1208-14.

21. Lübbert C, Wilhelms D, Worlitzsch D, Ettrich TJ, Behl S, Seufferlein T. Antibiotic treatment of enterococcal infections in gastroenterology with daptomycin-first experiences from the EU-CORE registry study (European Cubicin(R) Outcomes Registry and Experience). Z Gastroenterol. 2012;50(4):373-81.

22. Gonzalez-Ruiz A, Beiras-Fernandez A, Lehmkuhl H, Dohmen PM, Loeffler J, Chaves RL. Effectiveness 
and safety of daptomycin in complicated skin and soft-tissue infections and bacteraemia in clinical practice: results of a large non-interventional study. Int J Antimicrob Agents. 2013;41(4):372-8.

23. Seaton RA, Gonzalez-Ramallo VJ, Prisco V, Marcano-Lozada M, Gonzalez-Ruiz A, Gallegos B, Menichetti F, Loeffler J, Bouylout K, Chaves RL. Daptomycin for outpatient parenteral antibiotic therapy: a European registry experience. Int J Antimicrob Agents. 2013;41(5):468-72.

24. Dohmen PM, Guleri A, Capone A, Utili R, Seaton RA, González-Ramallo VJ, Pathan R, Heep M, Chaves RL. Daptomycin for the treatment of infective endocarditis: results from a European registry. J Antimicrob Chemother. 2013;68(4): 936-42.

25. Mutters NT, Mersch-Sundermann V, Mutters R, Brandt C, Schneider-Brachert W, Frank U. Control of the spread of vancomycin-resistant enterococci in hospitals: epidemiology and clinical relevance. Dtsch Arztebl Int. 2013;110(43):725-31.

26. Whang DW, Miller LG, Partain NM, McKinnell JA. Systematic review and meta-analysis of linezolid and daptomycin for treatment of vancomycinresistant enterococcal bloodstream infections. Antimicrob Agents Chemother. 2013;57(10): 5013-8.

27. Hayakawa K, Martin ET, Gudur UM, Marchaim D, Dalle D, Alshabani K, Muppavarapu KS, Jaydev F, Bathina P, Sundaragiri PR, Rajuri SD, Khatri J, Pogue JM, Lephart PR, Rybak MJ, Kaye KS. Impact of different antimicrobial therapies on clinical and fiscal outcomes of patients with bacteremia due to vancomycin-resistant enterococci. Antimicrob Agents Chemother. 2014;58(7):3968-75.

28. Vinh DC, Rubinstein E. Linezolid: a review of safety and tolerability. J Infect. 2009;59(Suppl 1):S59-74.
29. Narita M, Tsuji BT, Yu VL. Linezolid-associated peripheral and optic neuropathy, lactic acidosis, and serotonin syndrome. Pharmacotherapy. 2007;27(8):1189-97.

30. Sader HS, Farrell DJ, Flamm RK, Jones RN. Daptomycin activity tested against 164457 bacterial isolates from hospitalised patients: summary of 8 years of a Worldwide Surveillance Programme (2005-2012). Int J Antimicrob Agents. 2014;43(5):465-9.

31. Liu C, Bayer A, Cosgrove SE, Daum RS, Fridkin SK, Gorwitz RJ, Kaplan SL, Karchmer AW, Levine DP, Murray BE, J Rybak M, Talan DA, Chambers HF, Infectious Diseases Society of America. Clinical practice guidelines by the infectious diseases society of america for the treatment of methicillin-resistant Staphylococcus aureus infections in adults and children. Clin Infect Dis. 2011;52(3):e18-55.

32. Kullar R, Davis SL, Levine DP, Zhao JJ, Crank CW, Segreti J, Sakoulas G, Cosgrove SE, Rybak MJ. Highdose daptomycin for treatment of complicated gram-positive infections: a large, multicenter, retrospective study. Pharmacotherapy. 2011;31(6):527-36.

33. Casapao AM, Kullar R, Davis SL, Levine DP, Zhao JJ, Potoski BA, Goff DA, Crank CW, Segreti J, Sakoulas G, Cosgrove SE, Rybak MJ. Multicenter study of high-dose daptomycin for treatment of enterococcal infections. Antimicrob Agents Chemother. 2013;57(9):4190-6.

34. DeRyke CA, Sutherland C, Zhang B, Nicolau DP, Kuti JL. Serum bactericidal activities of high-dose daptomycin with and without coadministration of gentamicin against isolates of Staphylococcus aureus and Enterococcus species. Antimicrob Agents Chemother. 2006;50(11):3529-34. 